\title{
O IMPACTO DOS GASTOS SOCIAIS SOBRE OS INDICADORES DE DESIGUALDADE E POBREZA NOS ESTADOS BRASILEIROS NO PERÍODO DE 2004 A 2009*
}

\author{
Jevuks Matheus de Araujo ${ }^{a}$ \\ Janielle do Amaral Alves ${ }^{b}$ \\ Cássio da Nóbrega Besarria ${ }^{c}$
}

\begin{abstract}
RESUMO: O objetivo deste artigo é analisar os efeitos dos gastos sociais em educação e saúde nos indicadores de pobreza e nos índices de desigualdade de renda no período de 2004 a2009. A metodologia utilizada foi a técnica econométrica de dados em painel com efeitos fixos, haja vista a adequação deste método aos dados disponíveis. Foi possível verificar que para o período analisado houve uma redução nos indicadores de pobreza para os Estados brasileiros, onde os efeitos do Programa Bolsa Família foram estatisticamente significativos. Entretanto, não foi possível observar impactos estatisticamente significativos do Programa sobre os índices de desigualdade de renda. Verificou-se ainda que os gastos sociais em educação e saúde também reduzem a pobreza, mas não é possível afirmar que estes tenham impactos significativos sobre a desigualdade de renda. Por fim, foi possível constatar o importante papel do crescimento econômico sobre a redução da pobreza e da desigualdade de renda.
\end{abstract}

PALAVRAS-CHAVE: Pobreza; desigualdade; gastos sociais.

CLASSIFICAÇÃO JEL: H50; H51; H52; H53; O12.

Artigo recebido em 31/07/2012 e aprovado em 30/08/2013.

a Estudante do Doutorado do Programa de Pós-Graduação em Economia da Universidade Federal de Pernambuco (PIMES/UFPE) e professor da Universidade Federal Rural de Pernambuco (UFRPE). Contato: jevuks@hotmail.com.

b Estudante de pós-graduação em Educação Ambiental e Sustentabilidade no Semiárido Pernambucano da Unidade Acadêmica de Serra Talhada da Universidade Federal Rural de Pernambuco (UAST-UFRPE). Contato: janielle_amaral@hotmail.com.

Estudante do Doutorado do PIMES/UFPE e professor da UFPE. Contato: cassiodanobrega@yahoo.com.br. 


\title{
THE IMPACT OF SOCIAL SPENDING OVER INDICATORS OF INEQUALITY AND POVERTY IN THE BRAZILIAN STATES IN THE PERIOD 2004-2009
}

\begin{abstract}
This paper aims to analyze the effects of social spending on poverty indicators and indexes of income inequality in the period 2004-2009. The methodology used was the econometric technique of panel data fixed effects, due to the suitability of this method to the data available. Results show that in the analyzed period reduction decrease in poverty indicators related to the Brazilian states where the effects of the Bolsa Família Program proved statistically significant. However, no evidence was found that the Bolsa Família Program have produced statistically significant effects on the rates of income inequality. It was also found that social spending on education and health care also reduces poverty, but it is not possible to state that they have produced significant effects on income inequality. Finally it was established the important role of economic growth on poverty reduction and income inequality.
\end{abstract}

KEYWORDS: Poverty; inequality; social spending. 


\section{INTRODUÇÃO}

Os problemas com a pobreza e a desigualdade de renda se fazem presente no Brasil desde a colonização, agravando-se com o desenvolvimento da sociedade, o surgimento da indústria, os avanços tecnológicos, enfim, com a solidificação do capitalismo, no qual a renda e o consumo tornaram-se variáveis essenciais na ordenação das classes que compõem a sociedade moderna. Durante boa parte do processo de formação econômica do Brasil, questões relacionadas à pobreza, bem como os meios para tentar solucioná-la, foram consideradas em segundo plano, levando a grandes disparidades entre os indivíduos no convívio social.

De acordo com Rocha (2008) na década de 1970 já existiam transferências de renda para pessoas pobres; entretanto, tais iniciativas não possuíam muita eficácia em sua assistência - as pessoas beneficiadas eram basicamente idosas ou portadoras de necessidades especiais que não possuíam renda suficiente para manter os gastos necessários à sobrevivência. Apenas em 1988, com a promulgação da Constituição Federal Brasileira, principalmente com a promulgação da Lei Orgânica da Assistência Social (LOAS), em 1993, é que as transferências de renda obtiveram maior ênfase, tanto por ter ampliado os atendimentos às pessoas necessitadas, quanto pelo valor repassado ter sido estabelecido em um salário mínimo.

Em 2003, foi implantado o Programa Bolsa Família (PBF), que reunia um conjunto de programas anteriores a ele, possibilitando maior abrangência na assistência às famílias carentes e permitindo ampliar o número de pessoas beneficiadas. Um ano após a criação do programa, cinco milhões de famílias estavam incluídas no mesmo, e assim havia expectativas favoráveis diante dos resultados positivos obtidos inicialmente (Rocha, 2008).

Os programas de transferência de renda, assim como o Bolsa Família, têm por objetivo acrescentar renda às famílias beneficiadas. Dados publicados sobre o perfil das famílias beneficiadas pelo Programa Bolsa Família explicitam que o benefício obtido corresponde a um percentual médio de $48 \%$ do rendimento familiar de 12,7 milhões de famílias assistidas (Coelho, Tapajós e Rodrigues, 2010).

Essa melhoria na renda das pessoas pobres impacta direta e indiretamente sobre a vida e a renda de outras pessoas, uma vez que, ao possuir rendimentos, de certa forma as famílias têm seu consumo estimulado (para suprir as necessidades básicas), aquecendo assim o comércio local, que se expande com a renda gerada.

Marinho, Linhares e Campelo (2011) acreditam que os programas sociais do governo proporcionam melhor foco na questão distributiva, sobre as pessoas que mais necessitam. Entretanto, outros autores divergem desse ponto de vista, como Rocha (2005, 2008) e Oliveira, Zabot e Schneider (2009), os quais identificaram em seus estudos, de 
modo geral, que há a necessidade de mais foco no atendimento às pessoas carentes, para que haja, de fato, diminuição no número de pessoas pobres, melhor distribuição no nível de renda e consequentemente melhores condições de vida para a população como um todo.

Este trabalho tem como objetivo analisar o impacto do Programa Bolsa Família e os gastos sociais em educação e saúde na redução das desigualdades de renda e na pobreza dos estados brasileiros no período 2004 a 2009.

Além dessa introdução, o artigo apresenta-se divido em mais quatro seções. $\mathrm{Na}$ segunda são apresentados conceitos de pobreza e os seus determinantes, presentes na literatura teórica e empírica. Na terceira seção é exposta a metodologia de estimação para dados em painel. Na quarta é feita a demonstração dos resultados para a estimação. Na quinta e última seção encontram-se as considerações finais.

\section{ASPECTOS TEÓRICOS}

Esta seção do trabalho pretende expressar os principais conceitos de pobreza discutidos na literatura e as suas relações com os outros determinantes, tais como desigualdade social e de renda, índice de desenvolvimento humano e a intervenção governamental.

\subsection{POBREZA}

Como conceituar a pobreza? Para Rocha (2003), não há uma definição clara para a pobreza, mas, de maneira comparativa, pode ser considerado um estado no qual as pessoas não são assistidas de forma apropriada em suas necessidades "básicas".

Para o Banco Mundial (1990, p. 27), a pobreza define-se como a "incapacidade de atingir um padrão de vida mínimo". O que se pode entender sobre "padrão de vida mínimo", ainda de acordo com o Banco Mundial, é a análise do consumo por meio de uma predeterminação das necessidades consideradas básicas e deve corresponder a uma renda que possibilite a interação do indivíduo na sociedade.

Para Myles (1995) a pobreza é uma condição indicativa da ausência de renda, além de baixo consumo e de um nível de bem-estar aquém do desejado. A dúvida que emerge é sobre como determinar o padrão de renda a ser seguido ou mesmo estimado. $\mathrm{O}$ autor sugere duas alternativas: a percepção de pobreza absoluta e de pobreza relativa; e a distinção entre elas corresponde a transformações no nível de pobreza no decorrer dos anos, assim como no sucesso das medidas de combate a pobreza. 
De acordo com Crespo e Gurovitz (2002), a pobreza absoluta pode ser caracterizada como o estabelecimento de um valor mínimo necessário para manter digna a vida humana. De acordo com Myles (1995), esse “valor mínimo” estabelecido para o consumo independe do tempo ou da localização do indivíduo. Já a pobreza relativa possui ligação com a desigualdade de distribuição de renda; assim, de acordo com o segmento de vida das pessoas na sociedade, determinam-se as pessoas pobres como sendo aquelas que se encontram em pior situação na distribuição de renda ao serem relacionadas com as que estão em melhor situação (Crespo e Gurovitz, 2002).

Hoffmann (1998, p. 217) acredita que "são consideradas pobres todas as pessoas cuja renda for igual ou menor do que um valor preestabelecido, denominado linha de pobreza". O Instituto de Pesquisa Econômica Aplicada (IPEA) estabelece "a linha de pobreza como sendo igual ao dobro da linha de indigência” (Vieira, 2007, p. 16). Já a linha de indigência ou extrema pobreza é determinada sobre o valor da aquisição de uma cesta básica que englobe o mínimo de alimentação necessário para o indivíduo ${ }^{1}$.

Hoffmann (1998) ainda ressaltou que não há um parâmetro específico para definir se uma família (ou indivíduo) está em situação de pobreza. Isso ocorre porque é de acordo com o nível de renda que se estabelece a condição de vida do indivíduo, tais como acesso a serviços de saúde, educação, alimentação e lazer.

Em seu trabalho, Hamasaki (2003) expressou que, quando o desenvolvimento ocorre de forma diferente e desproporcional, produz-se a pobreza:

Parte considerável da população brasileira não foi beneficiada com oportunidades que lhes permitissem desenvolver capacidades e liberdades na realização de direitos que são considerados universais, como de ter acesso à educação, à saúde, de ter participação política, de ter um emprego e renda que lhes proteja da fome e da exclusão social. (Hamasaki, 2003, p. 18-19)

Wlodarski e Cunha (2005) e Diniz e Arraes (2005) apud Vieira (2007) também consideraram que a origem da pobreza no Brasil não está na escassez de recursos; ao mesmo tempo, afirmaram que o Brasil não é considerado um país pobre e sim um país que abriga muitos pobres. Os recursos existentes no país são considerados suficientes para sanar a desigualdade e a pobreza, sendo necessária, apenas, uma revisão no modo como os mesmos estão sendo aplicados.

O estudo realizado por Barros, Henriques e Mendonça (2000) demonstrou que o problema da pobreza no Brasil poderia ser explicado, sobretudo, por meio da má distribuição dos recursos existentes e não pela escassez dos mesmos. Ao mesmo tempo,

1 Podendo haver variações entre estados e regiões. 
compararam o nível de pobreza existente no Brasil com o dos demais países que possuem renda per capita semelhante; concluíram que o Brasil possui um nível de pobreza expressivamente maior do que a média dos outros países comparados, sustentando a ideia anterior de que a intensidade da pobreza pode ser gerada pela distribuição desigual dos recursos.

Hamasaki (2003) admitiu que o Brasil, mesmo tendo alcançado níveis de crescimento econômico expressivos em períodos distintos na história recente, não logrou produzir uma melhoria significativa nos seus índices de desenvolvimento, principalmente nos que medem a pobreza e a distribuição de renda. Assim, é importante ressaltar que o crescimento econômico por si só não é suficiente para reduzir os níveis de pobreza, haja vista a forte concentração de renda ocasionada por melhorias existente na economia brasileira. Como destaca Marinho e Soares:

A desigualdade na distribuição de renda é responsável pelo fato do crescimento econômico ser relativamente ineficiente na redução da pobreza, isto é, o efeito do crescimento econômico sobre a redução da pobreza é menor no Brasil do que em outros países que alcançaram o mesmo nível de renda. (2003, p. 2)

Coelho, Tapajós e Rodrigues (2010) adotaram esse mesmo ponto de vista, argumentando que o crescimento não ocorre de forma homogênea para toda a população, o que implica que a desigualdade reduz a eficiência do crescimento econômico no combate a pobreza.

Em 2000, o desenvolvimento explicitado pelo crescimento econômico constituiu uma nova agenda de discussão, com o compromisso assinado por 189 países, denominado de Declaração do Milênio² . Kageyama e Hoffmann (2006) enunciam o bem-estar e a redução da pobreza como sendo os objetivos centrais da Declaração do Milênio. É notável que a pobreza não seja igual para todos em todas as regiões, além de serem diversos os fatores que influenciam o seu surgimento ou sua manutenção no mundo. Há inúmeros índices que servem à identificação e à interpretação das causas e dos impactos da pobreza e da desigualdade; a seguir, é feita; a seguir é feita a apresentação de alguns desses índices.

\footnotetext{
A Declaração do Milênio das Nações Unidas foi aprovada na Cimeira do Milênio, realizada em setembro de 2000, na cidade de Nova Iorque. Os representantes dos 191 países envolvidos estabeleceram oito Objetivos de Desenvolvimento do Milênio, que abrangem desde a redução de até metade da pobreza extrema, passando pela diminuição do alastramento do HIV/SIDA, até a educação de crianças e jovens, matriculando-os em escolas primárias até o ano 2015.
} 


\subsection{CRESCIMENTO ECONÔMICO E POBREZA}

O Relatório de Desenvolvimento Humano de 2011, de acordo com o PNUD (2011), demonstrou que a América Latina, apesar de ter apresentado uma diminuição gradual da pobreza nos últimos anos, ainda é considerada a região que possui uma das maiores disparidades quanto à desigualdade de renda, principalmente os países da Argentina, Brasil, Honduras, México e Peru. Ainda de acordo com o relatório, dentro da região, o país que possui maior proporção de pobres é o Haiti, que é também um dos que apresenta maiores desigualdades em seus índices, tanto de desenvolvimento quanto de pobreza "multidimensional"3.

Os países mais ricos, considerados como os primeiros no Índice de Desenvolvimento Humano (IDH $)^{4}$ no ano de 2011, quando avaliados pelo IDH Ajustado à Desigualdade (IDHAD), deslocam sua colocação para baixo,como por exemplo, Estados Unidos, Coreia do Sul e Israel. Os Estados Unidos e Israel diminuem suas posições, sobretudo,por conta da desigualdade de renda; já na Coreia do Sul, o principal fator por trás de seu declínio de posição é a educação, segundo o PNUD (2011).

Já os que ocupam as menores colocações no IDH 2011 localizam-se na África Subsaariana e são: Guiné, República Centro-Africana, Serra Leoa, Burkina Faso, Libéria, Chade, Moçambique, Burundi, Níger e República Democrática do Congo. Mesmo com atuais evoluções, rendimentos dos habitantes desses países não deixam de ser precários, pois lidam com poucas oportunidades de escolaridade e baixa expectativa de vida (PNUD, 2011).

A pobreza está presente em todos os países; a diferença é o impacto que cada um sofre, diante das suas condições de riqueza. Hamasaki (2003) ressalta a importância do crescimento econômico como principal forma para reduzir a pobreza, isso porque se subtende que os países, ao ficarem mais ricos, experimentam redução do nível de pobreza e melhoria nos indicadores de bem-estar, devido à melhoria nas condições de renda.

Entretanto, o que se observa em países pobres, ou de extrema pobreza, é que eles sofrem um impacto pequeno com o crescimento, dada a forma de distribuição e o acesso às riquezas geradas, que são divididas de maneira desproporcional. Assim,

\footnotetext{
"O Índice de Pobreza Multidimensional (IPM) examina os fatores no âmbito familiar, como o acesso a água potável, combustível para cozinhar e serviços de saúde, assim como bens de consumo básicos e padrões de construção de casas. Juntos, esses indicadores fornecem um retrato mais completo da pobreza do que as medidas de renda sozinhas" (PNUD, 2011).

4 O Índice de Desenvolvimento Humano (IDH) engloba os indicadores de esperança de vida, escolaridade e renda, de acordo com o Programa das Nações Unidas (PNUD), é o índice que melhor especifica o desenvolvimento humano.
} 
ainda segundo Hamasaki (2003), é perceptível que o crescimento econômico exerce forte influência no sentido da diminuição da pobreza, mas ainda não é o bastante para que isso de fato ocorra, visto que, conforme a desigualdade aumenta, menores serão as influências do crescimento econômico sobre a redução da pobreza.

De acordo com Rocha (2003), é papel do Governo intermediar a posição de desigualdade existente, a fim de proporcionar igualdade a todos, ou ao menos diminuir os conflitos daí decorrentes,por meio de assistência às populações carentes através de transferências de renda que atendam às necessidades básicas de cada indivíduo.

\subsection{A INTERMEDIAÇÃO DO GOVERNO}

Alguns países em desenvolvimento, assim como o Brasil, possuem programas que têm por objetivo assistir socialmente as famílias e os indivíduos que estão em situação de pobreza. Os programas de transferências de renda visam melhorar o poder de compra das famílias em situação de pobreza. De acordo com Silva, Yazbek e Giovanni (2004, p. 131, apud Costa, Salvato e Diniz, 2008) os programas de transferência de renda são designados a efetuar, como o próprio nome diz, uma transferência de renda para as famílias carentes. Os programas surgem como auxílio para manutenção financeira das famílias, isto é, devem atuar como subsídio para que elas possuam uma renda que constituam o mínimo necessário para sua sobrevivência.

Após a aprovação da Lei Orgânica da Assistência Social (LOAS), no Brasil,em 1993, os programas de assistência social passaram por um procedimento de formação pública administrado de forma participativa. Essa lei tem o objetivo de melhorar a estrutura existente das políticas sociais no país, gerando novos programas de caráter nacional, como o Bolsa Escola e o Bolsa Alimentação. Esses programas não obtiveram muito sucesso em sua abrangência, passando por transformações anos depois (Oliveira, Zabot e Schneider, 2009).

Bichir (2008) e Santana (2007) expõem que os programas de transferências de renda, a princípio, atenderam algumas cidades da região Centro-Oeste do país, por volta da década de 1990. Posteriormente, obtiveram destaque em âmbito nacional com o programa Bolsa Escola, em 2001, durante o governo de Fernando Henrique Cardoso. Posteriormente, ocorreu a união dos vários programas existentes (Auxílio Gás, Bolsa Escola, Bolsa Alimentação e Cartão Alimentação), originando o Programa Bolsa Família, em 2003, durante o governo Lula. Esse, por sua vez, ganhou méritos pela ampliação da cobertura do programa em favor das famílias necessitadas, principalmente com a fundação do Ministério do Desenvolvimento Social e Combate à Fome (MDS), em 2004. 


\subsubsection{BOLSA FAMÍLIA}

O Programa Bolsa Família (PBF) é um programa com condicionalidades mediante a transferência de renda, que objetiva beneficiar as famílias em estado de pobreza ou pobreza extrema (BRASIL, 2011). Santana (2007) expõe que o governo determina condições a serem cumpridas pelas famílias para, assim, garantir-lhes o direito de receber regularmente seu benefício. Essas condições são:

Acompanhamento de saúde e do estado nutricional das famílias, ou seja, todos os membros da família beneficiária devem participar do acompanhamento de saúde, principalmente as gestantes e mães que amamentam que devem fazer exame pré-natal, participar de palestras educativas desenvolvidas pelas equipes de saúde sobre aleitamento materno e alimentação saudável; a freqüência à escola, quando todas as crianças em idade escolar (de 6 a 15 anos) devem estar matriculadas e freqüentando o ensino fundamental; por fim, todas as famílias beneficiárias devem participar de ações de educação alimentar oferecidas pelo Governo Federal, estadual e/ou municipal, quando oferecidas. (Santana, 2007, p. 5)

Essas “condições” impostas atuam como estímulos por parte do Governo para que as famílias efetivamente tenham acesso a benefícios sociais que são seus por direito, mas que geralmente têm dificuldades em consegui-los, dada a precariedade que envolve seus lares. Assim, além de beneficiar financeiramente, o PBF assiste as famílias nas mais variadas necessidades para uma vida digna.

O Programa Bolsa Família atende a nível nacional mais de 13 milhões de famílias. O valor recebido por cada família depende da renda familiar per capita (até R\$140), da quantidade dos filhos e da idade dos mesmos, e varia entre R\$ 32 e R\$306, sendo mais bem especificadas as variações dos valores recebidos no Quadro 1. O programa é gerido de forma conjunta por órgãos da esfera federal, estadual e municipal, que buscam aprimorar, expandir e fiscalizar a sua execução (BRASIL, 2011).

Quadro 1- Critérios de elegibilidade e valores dos benefícios do Programa Bolsa Família

\begin{tabular}{|c|c|c|c|c|}
\hline \multicolumn{2}{|c|}{ Critério de elegibilidade } & \multirow{2}{*}{$\begin{array}{l}\text { Ocorrência de Crianças/ } \\
\text { Adolescentes 0-15 Anos, } \\
\text { Gestantes e Nutrizes }\end{array}$} & \multirow{2}{*}{$\begin{array}{l}\text { Quantidade e Tipo } \\
\text { de Benefícios }\end{array}$} & \multirow{2}{*}{$\begin{array}{c}\text { Valores do } \\
\text { Benefício } \\
\text { (R\$) }\end{array}$} \\
\hline $\begin{array}{l}\text { Situação das } \\
\text { Famílias }\end{array}$ & $\begin{array}{l}\text { Renda Mensal } \\
\text { per capita }\end{array}$ & & & \\
\hline \multirow{3}{*}{ Situação de pobreza } & \multirow{3}{*}{$\begin{array}{l}\text { De R } \$ 60,01 \text { a } \\
R \$ 120,00\end{array}$} & 1 Membro & (1) Variável & 18,00 \\
\hline & & 2 Membros & (2) Variável & 36,00 \\
\hline & & 3 ou + Membros & (3) Variável & 54,00 \\
\hline \multirow{4}{*}{$\begin{array}{l}\text { Situação de extrema } \\
\text { pobreza }\end{array}$} & \multirow{4}{*}{ Até $R \$ 60,00$} & Sem ocorrência & Básico & 58,00 \\
\hline & & 1 Membro & Básico + (1) Variável & 76,00 \\
\hline & & 2 Membros & Básico + (2) Variável & 94,00 \\
\hline & & 3 ou + Membros & Básico + (3) Variável & 112,00 \\
\hline
\end{tabular}

Fonte: Santana (2007, p. 5). 
Há uma vasta literatura no Brasil sobre pobreza e desigualdade de renda, abrangendo diversas variáveis que explicam ou influenciam a intensidade dos fatores estudados, principalmente dados referentes ao Programa Bolsa Família, índice de Gini, índice de Theil, renda per capita entre outros. Na próxima seção do artigo serão expostos alguns trabalhos relacionados à diminuição dos níveis de pobreza e desigualdade de renda através da implantação dos programas de transferência de renda do Governo.

\subsection{ESTUDOS EMPÍRICOS APLICADOS AO BRASIL}

Guimarães (2006) investiga a ligação entre o crescimento econômico, a distribuição de renda e a pobreza, entre os anos de 2001 e 2005. O estudo embasa-se em três modelos: o de decomposição, que faz jus às alterações existentes pelos indicadores de pobreza, bem como às suas variações; o de elasticidade, que simula as consequências ocorridas mediante diferenciações na renda e nos indicadores de concentração diante da pobreza; e o modelo que faz a integração entre a desigualdade de renda e o crescimento econômico mediante o mais elevado nível de renda. Obteve como resultados uma diminuição na concentração de renda e redução significativa nas medidas de pobreza. Por meio da decomposição das variações de medidas de pobreza, percebeu-se que o principal responsável pela diminuição da pobreza é o crescimento econômico. Entretanto, não é suficiente, dada a forte concentração de renda verificada; a renda per capita nesses anos manteve-se constante. Ele averigua que, para haver informações mais precisas, a distribuição de renda deve ser analisada em estratos.

Rocha (2008) fez uma análise sobre a cobertura e a evolução das transferências de renda voltada às pessoas carentes do Brasil, especificamente do Programa Bolsa Família, utilizando simulações baseadas no ano de 2006, a fim de avaliar o possível impacto das "novas transferências" sobre os índices de pobreza, bem como a abrangência deste sobre a população-alvo. Os dados de referência são os equivalentes às Pesquisas Nacionais por Amostra de Domicílios (PNAD) de 2004 e 2006. Demonstrou-se que a eficiência do Programa Bolsa Família na transferência de renda é notável; entretanto, quanto à sua importância na luta contra a pobreza, o resultado não segue a mesma vertente. É perceptível que, quanto mais centralizado estiverem os benefícios, assim como quanto maior o número de famílias atendidas, mediante faixas de renda mínimas, melhores serão os resultados sobre a diminuição da pobreza para cada unidade monetária adicional na despesa com o programa.

Salvato et al. (2009) tiveram como objetivos do seu trabalho estimar as elasticidade de crescimento da pobreza e desigualdade da pobreza, bem como decompor a variação da pobreza pelos seus principais determinantes: crescimento e pobreza. Os 
anos analisados foram de 1995 a 2007, com exceção do ano 2000. Os modelos foram testados, utilizando-se diferentes elasticidades para as Unidades Federativas (UF), o modelo de dados empilhados (pooled least squared) e dados em painel com efeito fixo e aleatório. Os resultados indicaram muita discrepância entre os estados em suas elasticidades de crescimento da pobreza; os estados com menor elasticidade correspondem aos das regiões Norte e Nordeste, implicando dizer que os estados com menor riqueza são também os que possuem elasticidade de evolução da pobreza menor. Por fim, a decomposição da variação da pobreza apresenta unicamente os estados do Amapá, Rio de Janeiro, Roraima, Rio Grande do Sul e São Paulo como os que possuem elasticidade crescimento acima da média nacional, em conjunto com maior crescimento da renda relativa à média nacional. Entretanto, Bahia, Ceará, Maranhão, Mato Grosso do Sul, Mato Grosso, Paraíba, Piauí, Rio Grande do Norte, Sergipe e Tocantins apresentaram elasticidade crescimento abaixo da média nacional, em conjunto com menor crescimento da renda relativa à média nacional.

Oliveira, Zabot e Schneider (2009) fizeram uma análise da evolução dos programas de transferência de renda federal, comparando o Brasil com a Região Centro-Oeste, bem como os resultados obtidos pelos mesmos na melhoria dos indicadores sociais. Averiguou-se queda substancial no índice de Gini para os dois "locais", resultado que indica um fortalecimento da ligação entre os benefícios gerados pelos programas para distribuição de renda. Os autores também analisaram os impactos dos benefícios, por meio da variável frequência escolar, e perceberam que houve um aumento na mesma ao longo da última década. Por fim, foi feita uma crítica sobre a abrangência e a eficiência dos programas sobre a vida das pessoas beneficiadas, demonstrando que deve haver mais foco no que se refere às condições de melhoria de vida, sobretudo no que tange a educação e o aprendizado, para que no futuro as pessoas não necessitem mais do auxílio das transferências.

Barreto et al. (2009) buscaram identificar o efeito do aumento da renda média e da redução na desigualdade, por meio de agrupamento das regiões com base na renda per capita, o que levou à formação de um grupo com Norte e Nordeste e de outro com as regiões Sul, Sudeste e Centro-Oeste. A análise foi feita para os anos de 1995 e 2005, por meio de dados em painel com efeitos fixos e aleatórios, estimando-se as elasticidades renda-pobreza e desigualdade-pobreza. Como resultado, obteve-se que a elasticidade desigualdade-pobreza é maior que a renda-pobreza, o que implica dizer que os programas assistencialistas são mais eficazes na eliminação da pobreza do que propriamente a elevação da renda. Ao se analisar os impactos nas regiões, o grupo do Norte e Nordeste apresentou valores menores em suas elasticidades quando comparados aos valores das demais regiões (Sul, Sudeste e Centro-Oeste), implicando dizer que possuem níveis de 
pobreza mais resistentes às intervenções dos programas sociais e que seriam mais eficientes ações, como, programas de transferências que impactassem mais diretamente na redução da desigualdade.

Os estudos supracitados relacionam-se ao mesmo contexto e, mesmo assim, surgem pontos diferentes a serem tratados. Como a consequente elevação no nível de renda das pessoas mais pobres devido ao assistencialismo do PBF, bem como devido a elevações no crescimento econômico, há uma redução nos índices de pobreza, mas não na distribuição de renda. Uma vez que o atendimento não chegou a todas as pessoas, é preciso analisar e investigar a pobreza em cada grupo da sociedade e, assim, perceber as necessidades e dificuldades encontradas em seus subgrupos. Deve haver, além de maior abrangência no atendimento dos programas, mais foco nesse atendimento, isto é, averiguar realmente as pessoas que necessitam receber benefícios, para sanar suas necessidades básicas e, assim, poder haver uma melhora significativa em suas vidas.

Outra questão muito importante é quanto ao impacto dos benefícios para a sociedade e que contribuição para o futuro eles devem representar. É inegável a relevância dos programas, mas o melhor seria se as famílias não necessitassem deles futuramente, por terem alcançado um nível de instrução melhor, devido ao acesso a uma educação de qualidade, e consequentemente terem obtido emprego e renda.

\section{METODOLOGIA}

Nesta parte do artigo são expostas as variáveis utilizadas na pesquisa, bem como o modelo econométrico para estimar os impactos do Programa Bolsa Família (PBF) sobre os indicadores de pobreza e distribuição de renda.

\subsection{TÉCNICA ECONOMÉTRICA - DADOS EM PAINEL}

Segundo Maddala (2003, p. 308) "o termo dados em painel refere-se aos conjuntos de dados nos quais se tem dados sobre o mesmo indivíduo ao longo de vários períodos de tempo". Desta forma, consiste na combinação de dados de corte transversal e dados de séries temporais.

Hsiao (2003 apud Baltagi, 2005) apresentaram uma lista com benefícios de se utilizar dados em painel, e entre eles destacamos: permitir o controle da heterogeneidade individual; aumento do número de informações sobre amostra; dar uma maior variabilidade; reduzir a colinearidade entre as variáveis; e dar um maior grau de liberdade e mais eficiência. 
Outro importante benefício do uso de dados em painel é a capacidade de identificar e mensurar alguns efeitos que não são possíveis de se verificar com o uso de séries temporais ou dados de corte transversal (Baltagi, 2005). Desta forma, o modelo de dados em painel permite captar o efeito de variáveis que normalmente seriam omitidas em modelos de séries temporais ou corte transversal.

O modelo simples de dados em painel pode ser apresentado da seguinte forma:

$$
Y_{i t}=a+b X_{i t}+u_{i t}
$$

Onde $\mathrm{i}=1, \ldots, \mathrm{N}$ são os indivíduos, e $\mathrm{t}=1, \ldots, \mathrm{T}$ são os períodos de tempo.

Na equação 3.1 consideramos $a$ e $b$ como constantes, ou seja, igual para todos os indivíduos. Desta forma, a estimação da equação 3.1 não leva em consideração a heterogeneidade dos indivíduos. Pode-se considerar que a heterogeneidade esteja incluída no termo de erro; entretanto, isso aumenta a probabilidade de correlação entre o termo de erro e alguns dos regressores do modelo, ou seja, aumenta consideravelmente a possibilidade de os coeficientes estimados serem tendenciosos e inconsistentes.

A questão é como estimar o modelo levando em consideração a heterogeneidade dos indivíduos para que se possam obter estimadores que sejam consistentes e eficientes. Embora existam muitos $\operatorname{caminhos}^{5}$, destacaremos apenas o modelo de efeito fixo e o modelo de efeito aleatório.

No modelo de efeito fixo a estimação é realizada considerando que a heterogeneidade será captada pela parte constante do modelo, ou seja, o termo da constante será diferente de individuo para individuo:

$$
Y_{i t}=a_{i}+b X_{i t}+u_{i t}
$$

O termo da constante $a_{i}$ é invariante no tempo e diferente para cada indivíduo.

No modelo de efeito variável a estimação é realizada introduzindo a heterogeneidade no termo de erro. Neste caso tratamos a variável $a_{i}$ não como fixa, mas como uma variável aleatória. Ou seja,

$a i=a+\varepsilon_{i}$

Onde $\varepsilon_{i}$ é um termo de erro invariante no tempo e diferente para cada indivíduo.

Desta forma, podemos escrever o modelo de efeito variável:

$$
Y_{i t}=a+b X_{i t}+\varepsilon_{i}+u_{i t}
$$

\footnotetext{
5 Ver Baltagi (2005) e Gujarati (2011).
} 
Um ponto importante na estimação via o método de dados em painel é a escolha do modelo mais adequado. Qual modelo apresenta os melhores estimadores o modelo de efeito fixo ou o de efeito aleatório?

O teste de Hausman é utilizado para decidir qual é o modelo mais adequado. A hipótese nula $(\mathrm{H} 0)$ do teste define que o efeito aleatório é mais adequado e a hipótese alternativa (H1) define que o efeito fixo é mais adequado.

A estatística do teste de Hausman pode ser escrita da seguinte forma:

$$
H=\left(\hat{b}_{f e}-\hat{b}_{r e}\right)^{\prime}\left[\operatorname{Var}\left(\hat{b}_{f e}\right)-\operatorname{Var}\left(\hat{b}_{r e}\right)\right]^{-1}\left(\hat{b}_{f e}-\hat{b}_{r e}\right) \sim \chi_{k}^{2}
$$

Onde

$\hat{b}_{f e}$ e $\hat{b}_{r e}$ são respectivamente os vetores dos estimadores dos modelos de efeito fixo e aleatório; e

$K$ é o número de regressores.

O critério de escolha do teste:

Se $H>\mathrm{X}_{\mathrm{k}}^{2}$ rejeita-se $\mathrm{H} 0$.

\subsection{BASE DE DADOS E DESCRIÇÃO DAS VARIÁVEIS}

Seguindo a abrangência temporal entre os anos 2004 e 2009, a análise inclui todas as regiões brasileiras com a finalidade de fazer uma estimação do impacto do Programa Bolsa Família sobre os níveis de pobreza e desigualdade de renda. Os dados ${ }^{6}$ estudados referem-se a gastos estaduais com saúde e educação, número de pessoas em extrema pobreza, número de pessoas pobres, valor repassado pelo Programa Bolsa Família, índice de Theil, coeficiente de Gini e a taxa de crescimento do Produto Interno Bruto (PIB) industrial dos Estados.

Desta forma, montou-se um painel de dados considerando os Estados como indivíduos que foram acompanhados pelo período de seis anos. Isto permite ampliar a quantidade informações disponíveis para análise. A combinação de corte transversal com séries temporais possibilitou a construção de um painel com 162 observações, tornando mais confiável a inferência estatística a ser aplicada na pesquisa.

O valor anual repassado do Programa Bolsa Família (PBF) a cada unidade da federação e os indicadores de desigualdades (índice de Theil e coeficiente de Gini), bem

\footnotetext{
6 Todos referentes aos estados.
} 
como o número de pobres e de pessoas em extrema pobreza foram coletados no sítio do IPEADATA. As informações referentes aos gastos executados pelos Estados com educação e saúde foram obtidas no sítio da Secretaria do Tesouro Nacional (STN). Estes gastos se referem à intervenção do estado em áreas sociais com o objetivo de melhorar a qualidade de vida das famílias. Os dados referentes à taxa de crescimento do PIB industrial foram coletados no sítio do Instituto Brasileiro de Geografia e Estatística (IBGE).

As variáveis a serem consideradas no modelo são classificadas como dependentes e explicativas. Desta forma, as variáveis dependentes a serem estimadas são referentes a medidas de pobreza e desigualdade de renda. Os indicadores mais usados como medida de desigualdade de renda são o coeficiente de Gini e o índice de Theil, e o indicador de pobreza utilizado é o índice de Foster, Greer e Thorbecke, comumente chamado de FGT.

O coeficiente de Gini pode ser expresso por meio da curva de Lorenz (Figura 1), a área onde a está localizada é considerada a área de desigualdade. Assim, o índice de Gini varia entre 0 (zero) e 1 (um); quanto maior $\alpha$, maior é o índice de Gini e, consequentemente, maior concentração de renda Quanto ao grau de desigualdade na distribuição da renda domiciliar per capita entre os indivíduos, seu valor pode variar teoricamente desde 0 (zero), quando não há desigualdade (as rendas de todos os indivíduos têm o mesmo valor), até 1 (um), quando a desigualdade é máxima (apenas um indivíduo detém toda a renda da sociedade e a renda de todos os outros indivíduos é nula).

Figura 1 - Curva de Lorenz

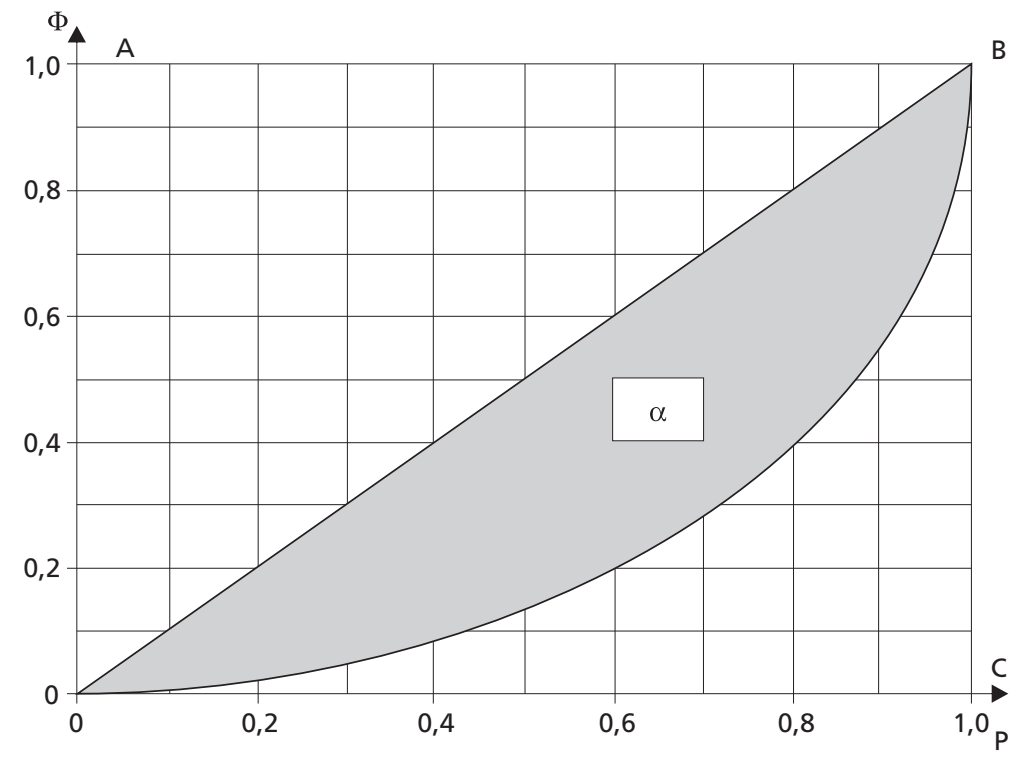


Segundo Hoffman, “(...) situações extremas de 'perfeita igualdade’ e 'perfeita desigualdade', não são observadas no mundo real. Dados sobre distribuição de renda, em qualquer região ou país, correspondem, sempre, a uma curva de Lorenz situada dentro do triângulo 0BC” (Hoffmann, 1998, p. 35). Ainda segundo o autor, quanto mais distante a curva estiver da linha de perfeita igualdade, maior será o grau de desigualdade da distribuição; a área $\alpha$, situada entre a linha de perfeita igualdade e a curva de Lorenz é a área de desigualdade.

O índice de Theil (assim como o de Gini) avalia o nível de desigualdade na distribuição de renda familiar per capita entre as pessoas, por meio de um logaritmo da razão entre as médias aritmética e geométrica de renda per capita, sendo o seu valor mínimo igual a zero (não há desigualdade na distribuição de renda) e tendendo a infinito quando há máximo de desigualdade.

O índice de Foster, Greer e Thorbecke $(\mathrm{FGT})^{7}$ possibilita estimar a magnitude da pobreza da população, considerando a distribuição de renda familiar per capita e a linha de pobreza. A intensidade da pobreza é considerada por meio da medida relativa do hiato de renda para cada pessoa pobre. A razão é enfatizada por $\alpha$, dadas a gravidade e a intensidade da pobreza no índice (Rocha, 2005).

Marinho, Linhares e Campelo (2011) caracterizam o indicador de pobreza como: $\mathrm{P}_{0}$ índice de proporção de pobres, $\mathrm{P}_{1}$ hiato médio de pobreza e o $\mathrm{P}_{2}$ hiato médio quadrático de pobreza, descritos a seguir.

$\mathrm{O}$ índice $\mathrm{P}_{0}$ é obtido através da quantidade de pessoas pobres em proporção a população total, resultando em pessoas cuja renda está abaixo da linha de pobreza. Esse indicador traz dificuldades, pois, ao haver qualquer alteração na renda de uma pessoa que está abaixo da linha de pobreza, o índice permanece o mesmo; dessa forma, ele detém apenas a extensão da pobreza, não demonstrando sensibilidade sobre a intensidade da pobreza.

$\mathrm{O}$ índice $\mathrm{P}_{1}$ é conhecido como o hiato médio da pobreza e apresenta o valor médio da distância dos pobres em relação à linha de pobreza, examinando a intensidade de pobreza para o conjunto da população pobre através do cálculo do desvio médio entre a renda dos pobres e o valor da linha de pobreza. Ele é explicado como referência do déficit de pobreza, isto é, o que for necessário para que a renda de todas as pessoas pobres seja elevada à linha de pobreza, por meio de transferências de renda.

$\mathrm{O}$ índice $\mathrm{P}_{2}$ faz referência à distância média ao quadrado das pessoas pobres em relação à linha de pobreza, podendo ser considerado um forte indicador de rigidez

Neste artigo foi considerado para análise do indicador de pobreza: o FGT, para o qual se faz referência a pessoas pobres e em extrema pobreza, satisfazendo os índices $\mathrm{P}_{0}$ e $\mathrm{P}_{2}$, descritos nesta seção. 
da pobreza; ao mesmo tempo esse índice considera a desigualdade na distribuição de renda entre os indivíduos pobres.

Ao utilizar esses indicadores de pobreza $\left(\mathrm{P}_{0}, \mathrm{P}_{1}\right.$ e $\left.\mathrm{P}_{2}\right)$ na formulação de políticas publicas direcionadas a solução da pobreza, percebe-se que a proporção de pessoas pobres $\left(\mathrm{P}_{0}\right)$, possuem maior eficácia às políticas que elevam a renda dos menos pobres, isto é, aquelas que estão mais próximas da linha de pobreza; enquanto que o hiato médio de pobreza e ao quadrado $\left(\mathrm{P}_{1}\right.$ e $\mathrm{P}_{2}$, respectivamente) revela as pessoas que se localizam muito abaixo da linha de pobreza, tidas como miseráveis (Marinho, Linhares e Campelo, 2008).

No Quadro 2 apresenta-se um resumo sintético das variáveis observadas, bem como da relação esperada entre as variáveis explicativas e as variáveis dependentes. Espera-se que os resultados da estimação empírica confirmem as relações descritas.

Quadro 2 -Descrição das variáveis

\begin{tabular}{l|l|l}
\hline \multicolumn{1}{c|}{ Variável } & \multicolumn{1}{|c}{ Significado } & \multicolumn{1}{c}{ Sinal Esperado } \\
\hline Extrema pobreza & $\begin{array}{l}\text { Número de pessoas em domicílios com renda domiciliar per capita } \\
\text { inferior à linha de extrema pobreza (ou miséria) }\end{array}$ & Variável dependente \\
\hline Pessoas pobres & $\begin{array}{l}\text { Número de pessoas em domicílios com renda domiciliar per capita } \\
\text { inferior à linha de pobreza }\end{array}$ & Variável dependente \\
\hline Theil & Índice de Theil por UF & Variável dependente \\
\hline Gini & Coeficiente de Gini por UF & Variável dependente \\
\hline Bolsa Família & $\begin{array}{l}\text { Renda per capita das famílias referente ao Programa de Transferência } \\
\text { de Renda }\end{array}$ & Negativo \\
\hline Saúde & Valor gasto em saúde no ano & Negativo \\
\hline Educação & Valor gasto em educação no ano & Negativo \\
\hline Taxa de crescimento & Variação anual do PIB Industrial por UF & Negativo \\
\hline
\end{tabular}

Fonte: Elaboração própria.

\subsection{ESTRATÉGIA EMPÍRICA}

A estratégia de estimação empírica consiste na aplicação do método de dados em painel. Para obter os resultados foi utilizado o software STATA $10^{8}$. A análise teve os seguintes procedimentos: organização dos dados em forma de painel; estimação do modelo de

8 Os dados foram estimados usando a opção VCE (robust) que trata eventuais problemas de heterocedasticidade e autocorrelação. 
efeitos fixos; estimação do modelo de efeitos aleatório e para escolha do melhor modelo aplicou-se o teste de Hausman.

As variáveis foram estimadas com especificação logarítmica; logo, os coeficientes remetem às variações percentuais. Os modelos econométricos estimados podem ser representados pelas equações:

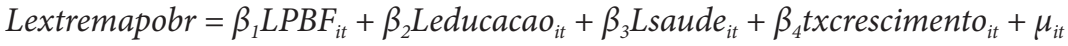

$$
\begin{aligned}
& \text { Lpobres }=\beta_{1} L P B F_{i t}+\beta_{2} \text { Leducacao }_{i t}+\beta_{3} \text { Lsaude }_{i t}+\beta_{4} \text { txcrescimento }_{i t}+\mu_{i t} \\
& \text { Gini }=\beta_{1} L P B F_{i t}+\beta_{2} \text { Leducacao }_{i t}+\beta_{3} \text { Lsaude }_{i t}+\beta_{4} \text { txcrescimento }_{i t}+\mu_{i t} \\
& \text { Theil }=\beta_{1} L_{P B F_{i t}}+\beta_{2} \text { Leducacao }_{i t}+\beta_{3} \text { Lsaude }_{i t}+\beta_{4} \text { txcrescimento }_{i t}+\mu_{i t}
\end{aligned}
$$

Onde $i$ representa a unidade da federação e $t$ é o tempo.

As variáveis Programa Bolsa Família (LPBF), educação e saúde tentam captar o impacto da intervenção direta do Governo, e a taxa de crescimento do PIB industrial tenta captar o impacto do crescimento econômico sobre os indicadores de desigualdade e pobreza.

\section{RESULTADOS}

Nesta seção do trabalho as variáveis são analisadas de forma descritiva, demonstrando a evolução ao longo do período, as variações e a disparidade entre os estados e regiões brasileiras, ressaltando-se, ainda, que os dados são estruturados em painel e abrangem os anos de 2004 a 2009. Também são discutidos os resultados obtidos com as estimações das equações 3.5, 3.6, 3.7 e 3.8 .

\subsection{ANÁLISE DESCRITIVA DAS VARIÁVEIS POR REGIÃO BRASILEIRA}

O Gráfico 1 mostra que, em 2004, a região com menor incidência média de pessoas em extrema pobreza foi a Centro-Oeste, enquanto a que apresentou maior incidência foi a região Nordeste. Com uma queda substancial ao longo dos anos analisados, a região Nordeste, ainda assim, em 2009, pode ser considerada a maior concentradora de pessoas indigentes, na comparação comas demais regiões.

Em relação ao número médio de pessoas pobres nas regiões brasileiras, verifica-se, no Gráfico 2, que o grande contingente pertencia à região Sudeste em 2004. A região com 
menor concentração de pessoas pobres é a região Centro-Oeste em todos os anos analisados. O número de pobres sofreu forte diminuição nas regiões Nordeste e Sudeste que, em 2009, apresentavam valores próximos. Constatou-se que a maior diminuição ocorreu na região Sudeste, a qual reduziu o número médio de pobres em 1.766 .350 pessoas.

Percebe-se, no Gráfico 3, que a região Sul, entre os anos de 2004 e 2009,apresentou o menor índice médio de Theil, mostrando-se uma região com relativa desigualdade na distribuição de renda, mas apresentando tendências de declínio. Por outro lado, a região Nordeste apresentou elevado índice médio, indicando uma forte concentração de renda.

Gráfico 1 - Número médio de pessoas em extrema pobreza por região (em milhares)

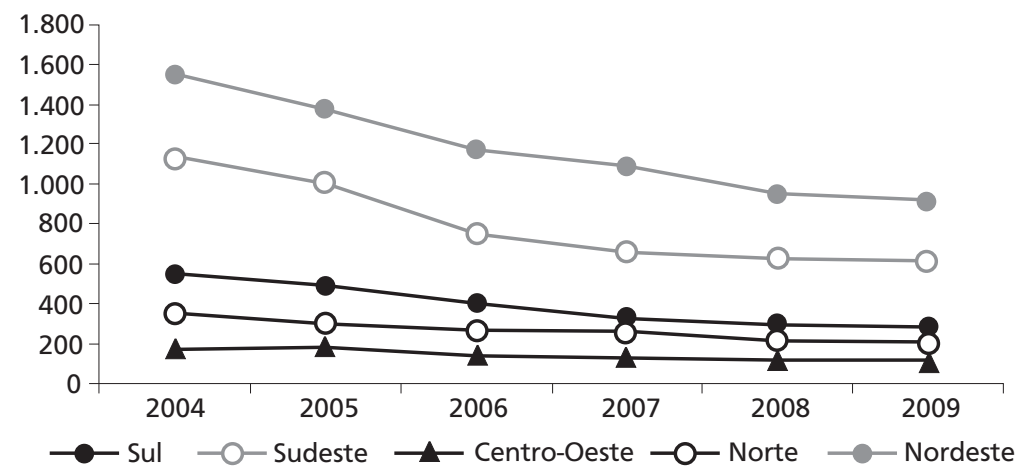

Fonte: Elaboração própria a partir dos dados da pesquisa.

\section{Gráfico 2 - Número médio de pessoas pobres por região (em milhares)}

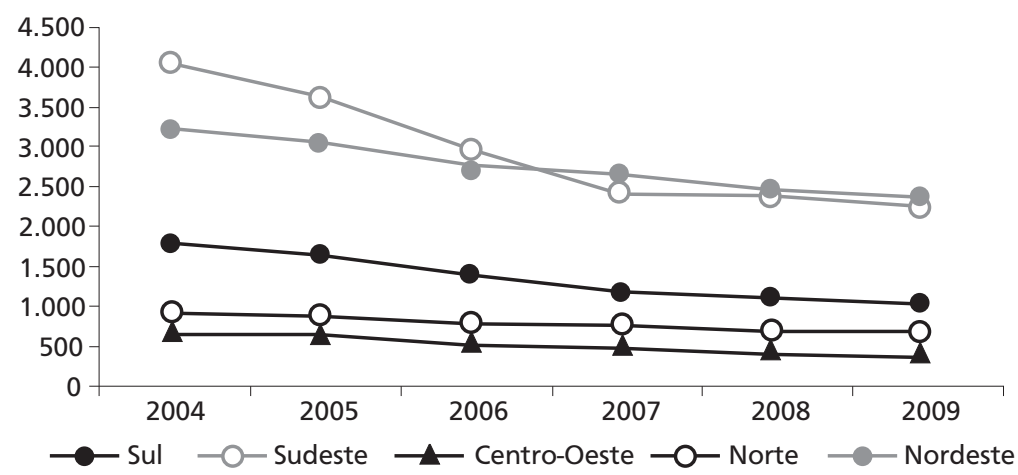

Fonte: Elaboração própria a partir dos dados da pesquisa. 
Gráfico 3 - Índice médio de Theil por região

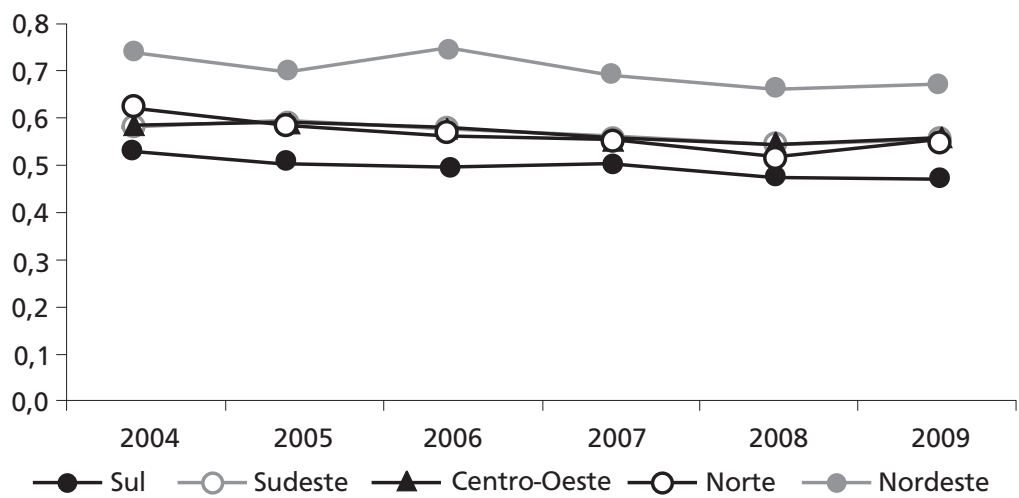

Fonte: Elaboração própria a partir dos dados da pesquisa.

O coeficiente de Gini (Gráfico 4) evidencia que a região Sul é a que apresenta menores disparidades na detenção da renda por um único indivíduo, isto é, em relação às demais regiões, esta é a que apresenta menos concentração de renda. O maior coeficiente médio é o relativo à região Nordeste, que por sua vez apresentou tendências de queda no período analisado, demonstrando uma diminuição na distribuição desigual da renda; entretanto, essa redução é muito suave.

O Gráfico 5 apresenta o valor médio repassado às famílias assistidas pelo programa federal Bolsa Família. A região Centro-Oeste demonstra, entre 2004 e 2009, ser a que recebeu menor repasse médio; já as regiões Sudeste e Nordeste, desde 2004, apresentaram valores aproximados, com grande tendência de crescimento e, em 2009, mais do que duplicaram o valor médio repassado às famílias.

\section{Gráfico 4 - Coeficiente médio de Gini por região}

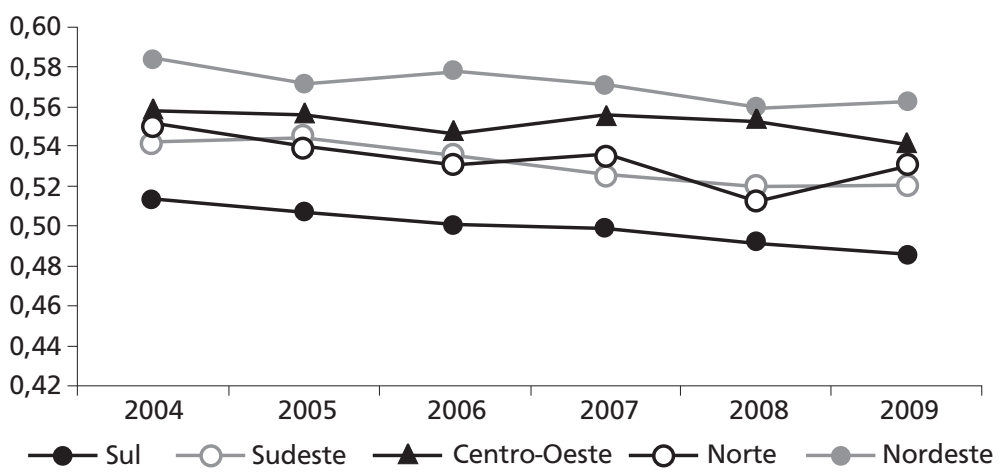




\section{Gráfico 5 - Valor médio transferido pelo Programa Bolsa Família (em milhões)}

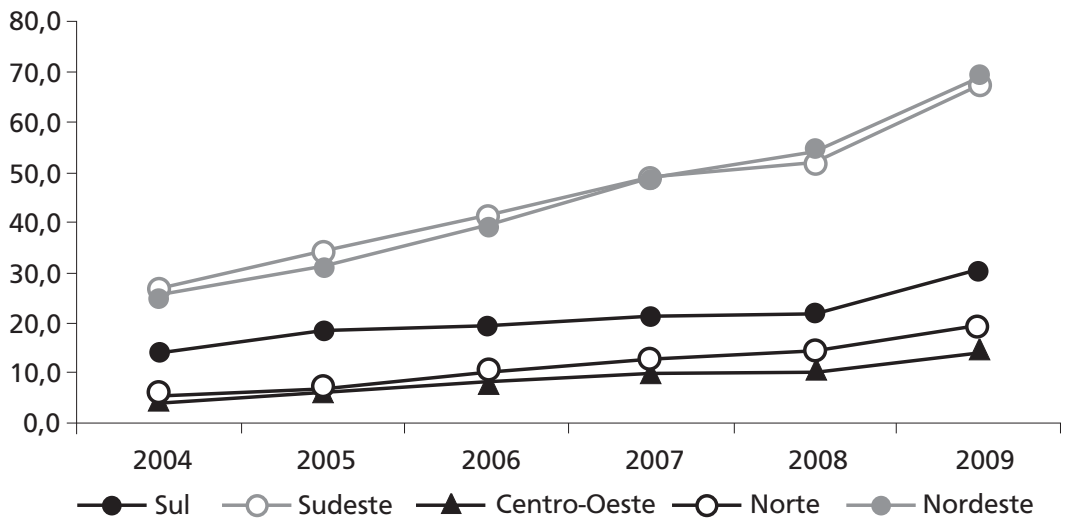

Fonte: Elaboração própria a partir dos dados da pesquisa.

A Tabela 1, a seguir, demonstra as estatísticas descritivas das variáveis analisadas neste trabalho. Verifica-se uma média anual de 644.331 pessoas em situação de extrema pobreza no Brasil. Ainda, averigua-se que o número de pessoas pobres varia bastante entre os estados, apresentando mínimo de 118.337 pessoas e máximo de 7.767.119 pessoas, indicando um grande contingente de pessoas que se situam abaixo da linha de pobreza. Da mesma forma, há grande variação entre os estados em relação ao Índice de Theil, que apresenta menor índice 0,39 (pouca desigualdade) e máximo de 1,05 (desigualdade elevada). Já o coeficiente de Gini apresenta uma média de 0,54, indicando que a desigualdade na distribuição de renda encontra-se em um nível intermediário.

Tabela 1 - Estatística descritiva das variáveis da análise de 2004 a 2009

\begin{tabular}{l|c|c|c}
\hline \multicolumn{1}{c|}{ Variável } & Média & Mínimo & Máximo \\
\hline Extrema pobreza & $644.331,30$ & $33.440,00$ & $3.341 .885,00$ \\
\hline Pessoas pobres & $1.785 .335,00$ & $118.337,00$ & $7.767 .119,00$ \\
\hline Índice Theil & 0,61 & 0,39 & 1,05 \\
\hline Coeficiente de Gini & 0,54 & 0,45 & 0,63 \\
\hline Bolsa família & $28.300 .000,00$ & $737.502,00$ & $157.000 .000,00$ \\
\hline Saúde & $1.370 .000 .000,00$ & $84.900 .000,00$ & $13.600 .000 .000,00$ \\
\hline Educação & $1.990 .000 .000,00$ & $178.000 .000,00$ & $22.900 .000 .000,00$ \\
\hline Taxa de crescimento & 1,12 & 0,93 & 1,33 \\
\hline
\end{tabular}

Fonte: Elaboração própria com base nos dados da pesquisa. 


\subsection{RESULTADOS ECONOMÉTRICOS}

Para análise dos resultados econométricos foram realizadas estimações para as 27 UF, no período de 2004 a 2009. Devido à composição dos dados preferiu-se adotar um modelo de estimação de painel e, assim, verificar o impacto das variáveis explicativas sobre as medidas de pobreza, bem como sobre a distribuição de renda nos estados brasileiros.

$\mathrm{Na}$ Tabela 2 as colunas 2, 3, 4 e 5 trazem respectivamente os resultados das estimações das equações 3.5, 3.6, 3.7 e 3.8. Na primeira coluna encontram-se as variáveis explicativas, e os coeficientes da estimação são referentes aos dados estimados com o modelo de efeito fixo.

Embora também tenha sido estimado o modelo de efeito aleatório para todas as estimações, o teste de Hausman recomendou o modelo efeito fixo como sendo mais adequado para avaliações dos resultados. Dessa forma, a discussão será restrita a observar os coeficientes do modelo de efeitos fixos.

$\mathrm{Na}$ coluna 2, verifica-se que todas as variáveis apresentaram os sinais esperados, demonstrando todas serem significantes do ponto vista estatístico. Assim, percebe-se que um aumento de $1 \%$ nos gastos com educação reduz a extrema pobreza em 0,29\%, bem como a elevação de $1 \%$ no valor do Programa Bolsa Família repassado às famílias impacta negativamente a extrema pobreza em $0,22 \%$. Averigua-se que o crescimento econômico também possui grande influência no combate à pobreza; considerando que o PIB se eleve em 1\%, a extrema pobreza reduz em 0,75\%; os gastos com saúde foram os que apresentaram menor variação (0,19\%), dada uma elevação de $1 \%$.

Em relação à coluna 3, todos os coeficientes mostraram-se significativos, com exceção dos gastos em saúde. Ao se considerar um aumento de $1 \%$ no valor gasto em educação, reduz-se o número de pessoas pobres em $0,22 \%$; igualmente, um aumento no PIB de $1 \%$ impacta na redução de pessoas pobres em aproximadamente, $0,30 \%$.

Os resultados apresentados nas colunas 2 e 3 evidenciam o papel das políticas públicas de intervenção mais direta no combate à pobreza,ressaltando o êxito do Programa Bolsa Família, que tem como maior objetivo melhorar a qualidade vida das pessoas, garantindo a elas a possibilidade de mais acesso a bens essenciais que possibilitam uma vida melhor.

Com relação à taxa de crescimento econômico, os resultados corroboram os pressupostos teóricos que definem o crescimento econômico como uma condição necessária (embora não suficiente) para melhoria da qualidade de vida da população.

A coluna 4, referente à estimação para o índice de Theil, demonstra que as variáveis educação e Bolsa Família não produzem impactos significativos do ponto de vista estatístico sobre a desigualdade de renda. Mesmo assim, os gastos com saúde apresentam resultados significativos, embora seu impacto seja muito pequeno. Uma elevação nos 
gastos com saúde de $1 \%$ refletirá em uma diminuição de 0,07\% no índice. A taxa de crescimento do PIB apresenta um impacto maior do que os gastos com a saúde; entretanto, seria necessário um crescimento de $10 \%$ no PIB para reduzir a desigualdade em 1,7\%.

Tabela 2 - Resultados das estimações

\begin{tabular}{|c|c|c|c|c|}
\hline Variáveis Explicativas & $\begin{array}{c}\text { Pessoas Extremamente } \\
\text { Pobres }\end{array}$ & $\begin{array}{l}\text { Pessoas } \\
\text { Pobres }\end{array}$ & $\begin{array}{c}\text { Indice de } \\
\text { Theil }\end{array}$ & Coeficiente de Gini \\
\hline LPBF & $-0,2245^{\star *}$ & $-0,1723^{\star \star}$ & $-0,0143$ & $-0,0050$ \\
\hline Lsaúde & $-0,1931^{\star}$ & $-0,1119$ & $-0,0708^{\star}$ & $-0,0199^{*}$ \\
\hline Leducação & $-0,2948^{\star * *}$ & $-0,2203^{\star \star \star}$ & 0,0135 & $-0,0050$ \\
\hline txcrescimento & $-0,7548^{\star * *}$ & $-0,3024^{*}$ & $-0,1708^{* *}$ & $-0,0379^{*}$ \\
\hline $\begin{array}{l}\text { Teste Hausman } \\
\text { Prob }>\text { chi } 2\end{array}$ & 0,0000 & 0,0000 & 0,0000 & 0,0000 \\
\hline $\mathrm{N}^{\circ}$ de obs. & 162 & 162 & 162 & 162 \\
\hline $\mathrm{N}^{\circ}$ de grupos & 27 & 27 & 27 & 27 \\
\hline Prob $>F$ & 0,0000 & 0,0000 & 0,0000 & 0,0000 \\
\hline $\mathrm{R}^{2}$ (within) & 0,7465 & 0,7546 & 0,1664 & 0,2585 \\
\hline
\end{tabular}

Nota: $\left.\left({ }^{*}\right),{ }^{* *}\right)$ e $\left({ }^{* *}\right)$ representam o nível de significância do coeficiente, respectivamente, em $10 \%, 5 \%$ e $1 \%$. Fonte: Elaboração própria a partir dos dados da pesquisa.

$\mathrm{Na}$ coluna 5 , todas as variáveis explicativas apresentam os sinais esperados; entretanto, como na coluna 4 , as únicas que se mostraram significativas são os gastos com saúde e a taxa de crescimento. Dada uma elevação de $1 \%$ nas variáveis gastos com saúde e taxa de crescimento, haveria uma queda no coeficiente de Gini de, respectivamente, $0,01 \%$ e $0,03 \%$.

Observa-se, pelos resultados das colunas 4 e 5, que o Programa Bolsa Família não contribuiu para redução da desigualdade de renda nos estados brasileiros. Esse resultado mostra a necessidade de outros mecanismos capazes de combater o problema da má distribuição de renda no país.

\section{CONSIDERAÇÕES FINAIS}

A análise descritiva dos resultados por região apontou grandes disparidades entre as regiões brasileiras, acima de tudo a região Nordeste; a mesma apresenta elevadas disparidades em todas as variáveis, com exceção do número médio de pobres e, com isso, distancia-se das demais regiões do país.

É importante ressaltar que durante o período analisado houve grande tendência de queda nos indicadores médios de pobreza; em relação ao índice médio de desigualdade na distribuição de renda, não houve grandes variações no decorrer dos anos analisados, despontando a região Nordeste como a mais desigual e a região Sul, como a menos desigual. 
Sobre o PBF, percebeu-se uma grande evolução do valor médio repassado às famílias beneficiadas, destacando-se as regiões Sudeste e Nordeste que, em 2009, obtiveram resultados semelhantes e basicamente duplicaram o valor médio repassado em relação ao ano de 2004.

Identificou-se também que a junção dos fatores de crescimento econômico com a intervenção pública, através do Programa Bolsa Família, proporciona melhoria da qualidade de vida das pessoas, o que implica em ampliação da mobilidade social (com ascensão das classes mais baixas), impactando sobre a redução dos indicadores de pobreza.Entretanto, não há evidências que confirmem a redução das enormes disparidades de renda que existem entre as classes sociais.

Os impactos positivos do PBF, na redução do indicativo de pessoas pobres, indicam que o programa cumpre com seu objetivo central. Embora não se possa considerar tal política uma como uma panaceia não se pode negar que o acesso a uma renda, mesmo que pequena, têm um efeito positivo na qualidade de vida das pessoas. Outro ponto importante é que o consórcio do programa com políticas de educação e saúde eleva o nível de bem estar e dá acesso a novas oportunidades às camadas menos abastadas da população.

Os índices referentes à desigualdade na distribuição de renda demonstraram que as variáveis Bolsa Família e gastos com educação não mostraram significância para uma possível diminuição da desigualdade, ao contrário das variáveis gastos com saúde e taxa de crescimento do PIB, que apresentaram significância e produziram impactos negativos sobre os índices. Esses impactos, no entanto, ainda não são suficientes para suprir a grande disparidade na distribuição, levando à necessidade de se reavaliarem as políticas adotadas, para serem mais eficazes e centradas.

A taxa de crescimento econômico não demonstra tanta eficácia devido ao grande nível de desigualdade existente no país, como bem caracterizou anteriormente Coelho, Tapajós e Rodrigues (2010) e Hamasaki (2003). Percebe-se que o crescimento econômico é de suma importância para a redução da pobreza, mas o mesmo não se apresenta tão eficaz quando há desigualdade. Isso ocorre porque, primeiro, deve-se buscar elevar a renda das pessoas mais pobres, e por meio de uma redistribuição possivelmente haverá melhores resultados nesses índices.

Dentro de uma agenda ampla de pesquisa social este trabalho limitou-se a compreender e descrever os efeitos da transferência de renda através do Programa Bolsa Família e dos gastos em educação e saúde e do crescimento econômico sobre indicadores de desigualdade e pobreza dos Estados brasileiros. Embora o objetivo do trabalho tenha sido atendido, fica evidente que os dados e a estratégia empírica são elementos bem particulares da abordagem dada à pesquisa. Desta forma, as discussões aqui abordadas podem ser trabalhadas utilizando outros métodos e outras variáveis que permitam mensurar o papel da intermediação do Governo na amortização dos problemas sociais aqui estudados. 
Destarte, é preciso fazer o rastreamento do problema da desigualdade na distribuição de renda, já que essa ao longo dos anos não demonstra variações significativas no sentido de sua redução. Apesar da diminuição nos indicadores de pobreza, conforme analisado neste estudo, verifica-se que a desigualdade não variou significativamente. Em vista disso, não apenas devem se averiguar quais variáveis de fato exercem impacto sobre a desigualdade, mas também o Governo deve buscar políticas mais eficientes na redução da mesma.

\section{REFERÊNCIAS BIBLIOGRÁFICAS}

BALTAGI, B. H. Econometric Analysis of Panel Data. 3 ed. London: John Wiley \& Sons, 2005.

BARRETO, F. A.; FRANÇA, J. M. S.; OLIVEIRA, V. H.; MANSO, C. A. O que mais impacta a redução da pobreza: o crescimento da renda ou redução da desigualdade? Estimativas para as regiões brasileiras e os setores da atividade econômica. Ensaio sobre Pobreza, n. 16, p. 1-23, ago. 2009.

BARROS, R. P.; HENRIQUES, R.; MENDONÇA, R. Desigualdade e pobreza no Brasil: retrato de uma estabilidade inaceitável. Revista Brasileira de Ciências Sociais, São Paulo, v. 15, n. 42, p. 123-142, fev. 2000.

BBC Brasil. Pobreza no mundo preocupa 94\% dos brasileiros. [on-line]. Disponível em: <http:// www.bbc.co.uk/portuguese/noticias/2010/01/100118_pesquisa_bbc_world_speaks_ rw.shtml>. Acesso em: 07 nov. 2011.

BICHIR, R. M. Novas experiências nas políticas de combate à pobreza: os programas de transferência de renda em São Paulo. In: Encontro Anual da Anpocs, 32, 2008, Caxambu. Anais eletrônicos... São Paulo: ANPOCS, 2008.

BIDERMAN, C.; ARVATE, P. (Orgs.) Economia do setor público no Brasil. Rio de Janeiro: Ed. Elsevier, 2004.

BRASIL. Ministério do Desenvolvimento Social. Disponível em: <http://www.mds.gov.br $>$. Acesso em: 11 nov. 2011.

BRASIL. Tesouro Nacional [on-line]. Disponível em: <http://www.tesouro.fazenda.gov.br/ estatistica/est_estados.asp>. Acesso em: 05 dez. 2011.

CHEIN, F.; LEMOS, M. B.; ASSUNÇÃO, J. J. Desenvolvimento desigual: evidências para o Brasil. Revista Brasileira de Economia, Rio de Janeiro, v. 61, n. 3, jul./set. 2007.

COELHO, M. F. P.; TAPAJÓS, L. M. S.; RODRIGUES M. (Orgs.) Políticas sociais para o desenvolvimento: superar a pobreza e promover a inclusão. Brasília: MDS, UNESCO, 2010.

COSTA, A. A. B.; SAlVATO, M. A.; DINIZ, S. C. Análise contrafactual do programa de transferência de renda bolsa família para o período 2004-2006. In: Encontro Nacional de Estudos Populacionais, 16. Anais... Caxambu, 2008. Disponível em: <http://www.abep.nepo. unicamp.br/encontro2008/docsPDF/ABEP2008_1320.pdf>. Acesso em: 04 out. 2011.

CRESPO, A. P. A.; GUROVITZ, E. A pobreza como um fenômeno multidimensional. Revista de Administração de Empresas, São Paulo, v. 1, n. 2, p. 1-12, jul./dez. 2002. 
DINIZ, M. B.; ARRAES, R. A. Desenvolvimento Econômico e Desigualdade de Renda no Brasil. In: Fórum BNB de Desenvolvimento, Encontro Regional de Economia, 10, Fortaleza, 2005. Anais eletrônicos... Fortaleza: BNB, 2005, p.1-26.

GARCIA, R. C. Iniqüidade Social no Brasil: Uma aproximação e uma tentativa de dimensionamento. Texto para Discussão, IPEA, n. 971, 2003. Disponível em: <http://www.ipea.gov.br/portal/ images/stories/PDFs/TDs/td_0971.pdf>. Acesso em: 06 out. 2011.

GIAMBIAGI, F.; CASTRO, L. B.; HERMANN, J.; VILLELA, A. (Orgs.). Economia Brasileira Contemporânea (1945-2004). 8 ed. Rio de Janeiro: Elsevier. 2005.

GUIMARÃES, P. W. Variação de renda familiar, desigualdade e pobreza no Brasil no período 2001 a 2005. Revista Economia e Desenvolvimento, n. 18, p. 73-99, 2006. Disponível em: <http:// cascavel.ufsm.br/revistas/ojs-2. 2.2/index.php/eed/article/viewFile/3473/2014>. Acesso em: 31 jul. 2011.

GUJARATI, D. N.; PORTER, D. C. Econometria básica. 5 ed. Porto Alegre: AMGH, 2011.

HAMASAKI, C. S. Programas de Garantia de Renda Mínima no Brasil: análise do impacto das transferências de renda sobre a pobreza. Tese de Doutorado, Programa de Pós-Graduação em Economia, Departamento de Economia, Universidade Federal de Pernambuco, Recife, 2003. Disponível em: <http://www.liber.ufpe.br/teses/arquivo/20040824150823.pdf >. Acesso em: 11 set. 2011.

HOFFMANN, R. Distribuição de renda: medidas de desigualdade e pobreza. São Paulo: Ed. da USP, 1998.

KAGEYAMA, A.; HOFFMANN, R. Pobreza no Brasil: uma perspectiva multidimensional. Economia e Sociedade, Campinas, v. 15, n. 1, p. 79-112, jan./jun. 2006.

KERSTENETZKY, C. L. Desigualdade e Pobreza: lições de Sen. Revista Brasileira de Ciências Sociais, v. 15, n. 42, p. 113-122, fev.2000.

LAVINAS, L. Pobreza e exclusão: traduções regionais de duas categorias da prática. Econômica, Rio de Janeiro, v. 4, n. 1, p. 25-59, jun. 2002.

MADDALA, G. S. Introdução à econometria. 3 ed. Rio de Janeiro: LTC, 2003.

MAIA, A. M. B. Pobreza urbana em Portugal. Coimbra: Universidade de Coimbra, Faculdade de Economia, dez. 2006.

MATIAS, J. S.; SALVATO, M. A.; BARRETO, F. A. F. D. Análise da qualidade do crescimento econômico nos estados brasileiros de 1995 a 2008: quão elásticos são os indicadores de pobreza com relação ao crescimento? Ensaio Sobre Pobreza, n. 22, p. 1-32, jun. 2010.

MARINHO, E.; SOARES, F. Impacto do crescimento econômico e da concentração de renda sobre a redução da pobreza nos estados brasileiros. In: Encontro Nacional de Economia, 31, Porto Seguro, Bahia, 2003.

MARINHO, E.; LINHARES, F; CAMPELO, G. Os programas de transferências de renda do governo impactam a pobreza no Brasil? Revista Brasileira de Economia, Rio de Janeiro, v. 65, n. 3, p. 267-288, jul./set. 2011.

MYLES, G. D. Public economics. Cambridge: Cambridge University Press, 1995. 
NEDER, H. D.; SILVA, J. L. M. Pobreza e distribuição de renda em áreas rurais: uma abordagem de inferência. Revista Economia Sociologia Rural, Rio de Janeiro, v. 42, n.3, p. 469-486, jul./ set. 2004.

OLIVEIRA, D. B. O.; ZABOT, U. C.; SCHNEIDER, Y. F. Eficiência dos programas de transferências de renda e o desenvolvimento sócio econômico regional. In: Ciclo de palestras em Ciências Sociais Aplicadas, 3, Sinop, MT, 19-23 out., 2009.

PROGRAMA DAS NAÇÕES UNIDAS PARA O DESENVOLVIMENTO (PNUD). Relatório do Desenvolvimento Humano 2010: A verdadeira riqueza das nações. Vias para o desenvolvimento humano. New York: PNUD, 2010.

PROGRAMA DAS NAÇÕES UNIDAS PARA O DESENVOLVIMENTO (PNUD). Relatório do Desenvolvimento Humano 2011: Sustentabilidade e equidade: um futuro melhor para todos. Disponível em: <http://hdr.undp.org/en/media/HDR_2011_PT_Complete.pdf $>$. Acesso em: 08 nov. 2011.

ROCHA, S. Impacto sobre a pobreza dos novos programas federais de transferência de renda. Revista de Economia Contemporânea, Rio de Janeiro, v. 9, n. 1, p. 153-185, jan./abr. 2005.

ROCHA, S.A evolução do programa Bolsa-Família brasileiro: funcionamento e impactos sobre a pobreza. Occasional Paper, University of Oxford, Brazilian Studies Programme, 2008.

ROCHA, S. Pobreza no Brasil: afinal, de que se trata? 1 ed. Rio de Janeiro: FGV, 2003.

RÜCKERT, I. N.; BORSATTO, M. L. Os programas de transferência de renda no RS. Fundação de Economia e Estatística, n. 70, Porto Alegre, Out. 2009.

SALVATO, M. A.; MATIAS, J. S.; BARRETO, F. A.; MANSO, C. A. Decomposição da variação da pobreza em efeito crescimento e desigualdade. Ensaio Sobre Pobreza, n. 20, p. 1-18, set. 2009.

SANTANA, J. A. A evolução dos programas de transferência de renda e o Programa Bolsa Família. In: Seminário População, Pobreza e Desigualdade. Anais... Belo Horizonte, 2007.

SOUZA, N. J. Desenvolvimento Econômico. 5 ed. São Paulo: Atlas, 2005, p. 1-27.

UGÁ, V. D. A categoria "pobreza" nas formulações de política social do banco mundial. Revista Sociologia e Política, Curitiba, n. 23, p. 55-62, nov. 2004.

UNIVERSIDADE FEDERAL DO RIO GRANDE DO SUL (UFRGS); PONTIFÍCIA UNIVERSIDADE CATÓLICA DE MINAS GERAIS (PUC-MINAS); PROGRAMA DAS NAÇÕES UNIDAS PARA O DESENVOLVIMENTO (PNUD); INSTITUTO DE DESENVOLVIMENTO HUMANO SUSTENTÁVEL (IDHS). (Orgs.) Pobreza e fome: objetivo 1: erradicar a extrema pobreza e a fome. Belo Horizonte: PUC Minas, IDHS, 2004.

VIEIRA, M. L. A contribuição das micro e pequenas empresas para a redução da pobreza no Brasil. Dissertação de Mestrado, Centro de Aperfeiçoamento de Economistas do Nordeste, Faculdade de Economia, Administração, Atuária, Contabilidade e Secretariado Executivo, Universidade Federal do Ceará, Fortaleza, 2007.

WLODARSKI, R.; CUNHA, L. A. Desigualdade social e pobreza como consequências do desenvolvimento da sociedade. In: Simpósio Internacional Processo Civilizador - Tecnologia e Civilização, 9, Ponta Grossa, PR, 2005. 